\title{
Synthesis of palladium and palladium sulfide nanocrystals via thermolysis of a Pd-thiolate cluster
}

\author{
Quanchen Feng, Weiyang Wang, Weng-Chon Cheong, Dingsheng Wang, Qing Peng, Jinpeng Li", \\ Chen Chen* and Yadong Li
}

\begin{abstract}
A novel one-pot approach to synthesize the tiara-like Pd(II) thiolate complex compound, $\left[\mathrm{Pd}\left(\mathrm{SCH}_{3}\right)_{2}\right]_{6}$, was developed. In this strategy, dimethyl sulfoxide (DMSO) was used as a thiolate source instead of methyl mercaptan $\left(\mathrm{CH}_{3} \mathrm{SH}\right)$. DMSO was first decomposed into $\mathrm{CH}_{3} \mathrm{SH}$ and formaldehyde (HCHO); then, the in situ as-formed $\mathrm{CH}_{3} \mathrm{SH}$ molecules reacted with palladium acetate, and formed $\left[\mathrm{Pd}\left(\mathrm{SCH}_{3}\right)_{2}\right]_{6}$. By tuning the reaction condition, the morphology of the $\left[\mathrm{Pd}\left(\mathrm{SCH}_{3}\right)_{2}\right]_{6}$ assemblies can change from microprism to nanosphere. The characterization of the pyrolysis product demonstrated that these two kinds of $\left[\mathrm{Pd}\left(\mathrm{SCH}_{3}\right)_{2}\right]_{6}$ assemblies with different shapes could further decompose into palladium or palladium sulfides through different pyrolysis conditions.
\end{abstract}

\section{INTRODUCTION}

Transition metal thiolates play important roles in helping us understand the biological processes and in the progress of coordination chemistry $[1,2]$. Thiolate ligands (SR) could bond with metal atoms in different coordination modes, terminal, $\mu_{2}$-bridging or $\mu_{3}$-bridging modes [3-5]. A large variety of thiolated transition metal clusters have been extensively synthesized and characterized, such as iron [6], cobalt [7], nickel [8-10], copper [10,11], zinc [12,13], palladium [14,15], silver [4,16,17], platinum [18] and gold $[5,19]$. These metal-thiolate clusters exhibit intriguing properties and potential applications in the fields of catalysis [20,21], optics [22,23] and magnetism [24,25]. Recently, self-assemblies of these individual metal-thiolate clusters into specific nano-architectures have also gained extensive concern [26-30]. Wu et al. [26,27] reported the synthesis of gold nanosheets and copper nanoribbons through the controlled self-assembly of $\mathrm{Au}_{15}$ and $\mathrm{Cu}_{12}$ clusters. The resulting $\mathrm{Cu}$ nanoribbons showed enhanced structural stability without lowering its catalytic activity in oxygen reduction reaction (ORR) [26].

Palladium nanostructures of different sizes and morphologies play crucial roles in organic catalysis [31-36], electrocatalysis [37], hydrogen storage [38], and surface plasmon resonance [39]. Its sulfides contain many kinds of compounds, including $\mathrm{PdS}, \mathrm{PdS}_{2}, \mathrm{Pd}_{3} \mathrm{~S}, \mathrm{Pd}_{16} \mathrm{~S}_{7}$, and $\mathrm{Pd}_{4}$ S. PdS is a semiconductor with an energy gap about 2 $\mathrm{eV}$ which endows it applications in catalysis [40-42] and semiconductor materials science $[43,44]$. A classic way to synthesize metals or metal sulfides is thermal decomposition of the corresponding metal thiolates under solvents or solventless conditions [45-47]. Palladium and palladium sulfides can also be synthesized through thermolysis of palladium thiolate clusters [46,47]. Yang et al. [46] reported the preparation of nearly monodisperse palladium sulfide (PdS) nanoparticles via the solution-phase thermolysis of a palladium (II) thiolate precursor, $\left[\mathrm{Pd}\left(\mathrm{SC}_{12} \mathrm{H}_{25}\right)_{2}\right]_{6}$. Jose et al. [47] synthesized Pd, PdS, and Pd@PdO core-shell nanoparticles via solventless thermolysis method.

Herein, we report a novel method to synthesize a palladium(II) thiolate complex, $\left[\mathrm{Pd}\left(\mathrm{SCH}_{3}\right)_{2}\right]_{6}$. In this method, dimethyl sulfoxide (DMSO) is used instead of methyl mercaptan $\left(\mathrm{CH}_{3} \mathrm{SH}\right)$. Compared with $\mathrm{CH}_{3} \mathrm{SH}$, DMSO is more readily available without irritating smell. The resulting complex $\left[\mathrm{Pd}\left(\mathrm{SCH}_{3}\right)_{2}\right]_{6}$ can self-assemble into different structures by finely tuning the reaction conditions. Furthermore, palladium and palladium sulfides $\left(\mathrm{Pd}_{4} \mathrm{~S}, \mathrm{PdS}\right.$, $\left.\mathrm{Pd}_{16} \mathrm{~S}_{7}, \mathrm{Pd}_{32} \mathrm{~S}_{14}\right)$ are obtained through the pyrolysis of these $\left[\mathrm{Pd}\left(\mathrm{SCH}_{3}\right)_{2}\right]_{6}$ assemblies under different temperatures and atmosphere.

\section{EXPERIMENTAL SECTION}

\section{Chemicals}

Analytical grade acetate acid, DMSO, ethylene glycol (EG) and ethanol were obtained from Beijing Chemical Reagents, China. Palladium (II) acetate [Pd(OAc) $\left.{ }_{2}, 98 \%\right]$ was purchased from Sinopharm Chemical Reagent Co., Ltd. (Shanghai, China). Cetyltrimethyl ammonium bromide (CTAB) was bought from Alfa Aesar. All chemicals were

Department of Chemistry and Collaborative Innovation Center for Nanomaterial Science and Engineering, Tsinghua University, Beijing 100084, China "Corresponding authors (emails: jinpeng-li@mail.tsinghua.edu.cn (Li J); cchen@mail.tsinghua.edu.cn (Chen C)) 
used as received without further purification.

\section{Synthesis of $\left[\mathrm{Pd}\left(\mathrm{SCH}_{3}\right)_{2}\right]_{6}$ microprismatic assemblies}

$12 \mathrm{mg}$ of $\mathrm{Pd}(\mathrm{OAc})_{2}$ was dissolved in $8 \mathrm{~mL}$ acetate acid and gave a bright yellow solution. Then, $8 \mathrm{~mL}$ DMSO and 8 mL EG were added under stirring. The mixed solution was heated to $130^{\circ} \mathrm{C}$ in oil bath and kept at this temperature for $3 \mathrm{~h}$. Then the mixture was cooled down to room temperature, and the orange precipitate was separated via centrifugation at 10,000 rpm for $5 \mathrm{~min}$, and further washed with ethanol for three times.

\section{Synthesis of $\left[\mathrm{Pd}\left(\mathrm{SCH}_{3}\right)_{2}\right]_{6}$ nanospherical assemblies}

$20 \mathrm{mg}$ of $\mathrm{Pd}(\mathrm{OAc})_{2}$ and $40 \mathrm{mg}$ of CTAB were dissolved in $8 \mathrm{~mL}$ acetate acid to form a yellowish red solution. Then, 8 $\mathrm{mL}$ DMSO and $8 \mathrm{~mL}$ EG were added under stirring. This mixed solution was heated to $130^{\circ} \mathrm{C}$ in oil bath and kept for $15 \mathrm{~min}$ at this temperature. Centrifugation and washing procedures were the same as described in microprismatic counterpart.

\section{Characterizations}

The samples were characterized by X-ray diffraction (XRD), using a Bruker D8 Advance X-ray powder diffractometer with monochromatized $\mathrm{Cu} \mathrm{Ka}$ radiation $(\lambda=1.5418 \AA)$. The operation voltage and current were $40 \mathrm{kV}$ and $40 \mathrm{~mA}$, respectively. Powder XRD data were recorded with a $2 \theta$ resolution of $0.02^{\circ}$ and a scan rate of $0.2 \mathrm{~s}$ per point. Transmission electron microscopy (TEM) images were recorded by a JEOL ModelJEM-1200EX working at an accelerating voltage of $100 \mathrm{kV}$. The $\mathrm{N}_{2}$ adsorption-desorption isotherms were collected using a Quantachrome Instruments Autosorb AS-6B at liquid temperature. Thermogravimetric analysis (TGA) of the sample was conducted on a TGA2050 (TA Corp.) thermogravimeter. The Fourier transform infrared (FT-IR) spectrum of the sample was collected on a Perkin-Elmer Spectrum GX FTIR spectrometer from 4000 to $450 \mathrm{~cm}^{-1}$. The UV/vis absorption spectrum of Pd clusters (dissolved in $\mathrm{CHCl}_{3}$ ) was recorded in standard quartz cu- vettes on a UV-2550 spectrophotometer (Shimadzu, Japan) at room temperature. The morphologies of the assemblies were characterized using a field-emission scanning microscope (FESEM) (LEO-1530) and the elemental composition of the material was determined by energy-dispersive X-ray spectroscopy (EDS) (Oxford 7426 attached to the FESEM) at the voltage of $20 \mathrm{kV}$.

\section{RESULTS AND DISCUSSION}

\section{Reaction mechanism of $\left[\mathrm{Pd}\left(\mathrm{SCH}_{3}\right)_{2}\right]_{6}$ complex}

Normally, to prepare $\mathrm{Pd}(\mathrm{II})$ thiolate complex, the corresponding thiol ligands should be used. In our synthesis process, DMSO is used to transform to methanethiol in situ, which can avoid stink and flammable regent during the synthesis. Upon heating, the initially transparent solution becomes cloudy within $15 \mathrm{~min}$. Photographs of different time during the synthesis are shown in Fig. S1. The proposed mechanism of the $\mathrm{Pd}$-thiolate complex formation is illustrated in Scheme 1. It has previously been reported that sulfoxides which do not possess $\beta$-hydrogens can be thermally rearranged to the corresponding sulphenates, the latter subsequently fragmenting into a thiol and a carbonyl compound [48]. In the present case of dimethyl sulfoxide, this reaction would result in the formation of methanethiol (2) and formaldehyde (3) likely via methyl methanesulphenate (1) [48]. Thus, the as-formed methanethiol reacts with palladium acetate, thereby giving us the undissolvable Pd-thiolate complex compound and acetate acid.

\section{Structure and properties of $\left[\mathrm{Pd}\left(\mathrm{SCH}_{3}\right)_{2}\right]_{6}$ complex}

Powder XRD data (Fig. 1a) demonstrates that the profile of the as-prepared sample perfectly matches to the previously determined crystal structure (Figs $1 \mathrm{~b}$ and c) [ref. no. 644152, Cambridge Crystallographic Data Centre (CCDC)] [49] which is reported as a private communication. The structure of $\left[\mathrm{Pd}\left(\mathrm{SCH}_{3}\right)_{2}\right]_{6}$ belongs to $R-3$ space group with $a=b=17.678 \AA, c=8.705 \AA$; $\alpha=\beta=90^{\circ}, \gamma=$ $120^{\circ}$. As seen in Fig. 1, in each cluster, the six palladium

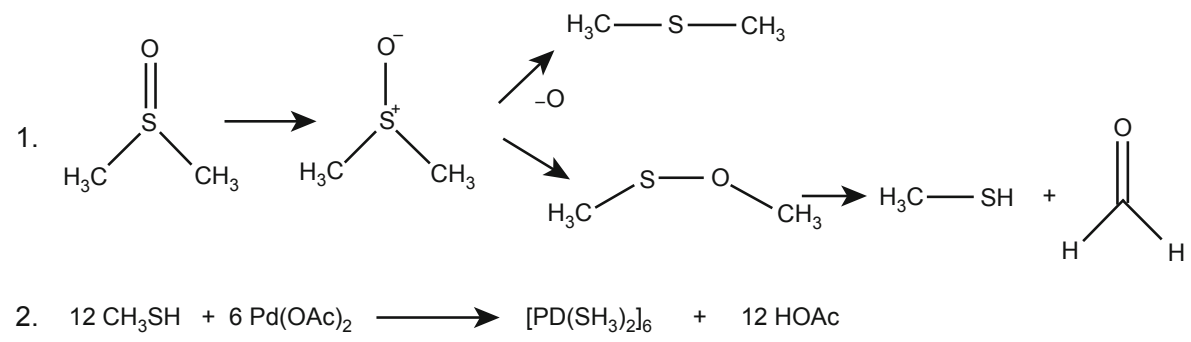

Scheme 1 Schematic illustration of the proposed mechanism for the formation of a Pd-thiolate complex. 

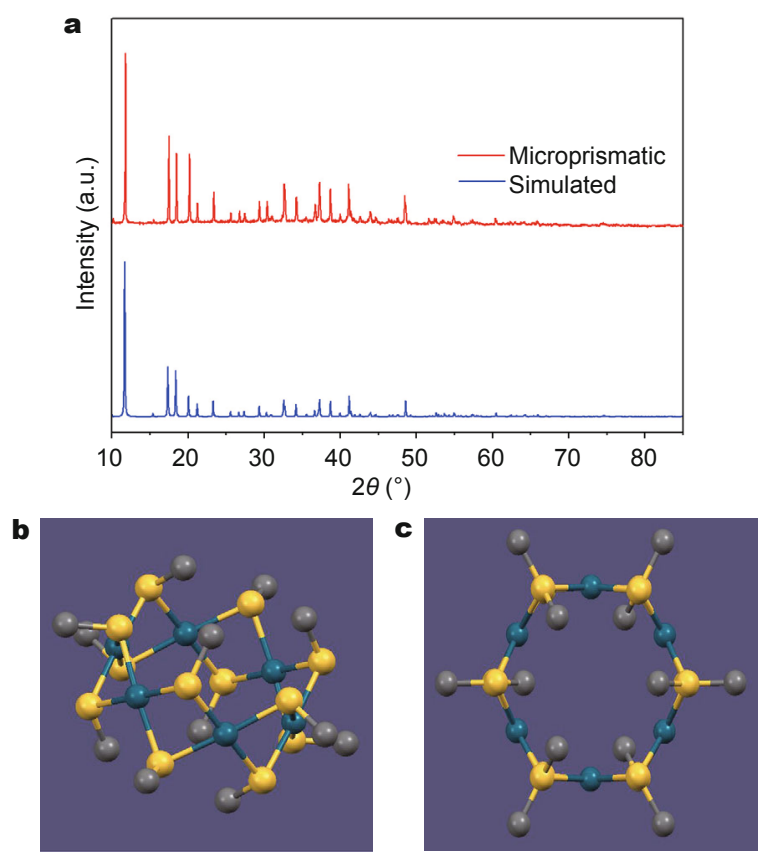

Figure 1 (a) XRD profiles of the as-prepared sample (red) with the calculated pattern (blue) according to the single-crystal data (CCDC-644152) from Mercury. Molecular structure of single cyclic $\left[\mathrm{Pd}\left(\mathrm{SCH}_{3}\right)_{2}\right]_{6}$ molecule, side view (b) and top view (c). Color legend: blue spheres, Pd atom; yellow spheres, $\mathrm{S}$ atom; gray spheres, $\mathrm{C}$ atom. All hydrogen atoms are omitted for clarity.

atoms form a hexagonal shape in a nearly planar style, the Pd...Pd distance gives an equal length of $3.126 \AA$, which is too long to form significant bonding between the neighboring palladium atoms. Four sulfur $\mu_{2}$-bridged thiolate ligands coordinate with each palladium atom with an approximately square-planar configuration. The average $\mathrm{Pd}-\mathrm{S}$ bond length is $2.332 \AA$, and the $\mathrm{S}-\mathrm{Pd}-\mathrm{S}$ bond angles vary in the range of $81.9-98.0^{\circ}$. All 12 sulfur atoms form two $\mathrm{S}_{6}$ hexagons parallel to the central $\mathrm{Pd}_{6}$ ring from both sides. The dihedral angle between the $\mathrm{PdS}_{4}$ coordination planes is $176.4^{\circ}$. The average $S \cdots S$ distance in $S_{6}$ rings is $3.513 \AA$, indicating no existence of $\mathrm{S}-\mathrm{S}$ bond. The whole cluster assembles into a triple-layered tiara-like structure with a height of $\sim 3.056 \AA$. And its symmetry is close to $\mathrm{D}_{6 \mathrm{~h}}$. The methyl thiolate groups are alternately located in either parallel or perpendicular direction to the $S_{6}$ rings (Fig. 1b). According to theoretical investigation [50], the $\mathrm{Pd}-\mathrm{S} \pi$ bonding orbitals distributing throughout the palladium ring play a pivotal role in constructing and stabilizing the characteristic tiara-like structure. Such atomic arrangement has a triple-layered tiara-like structure and has also been found in other analogous $\left[\mathrm{Pd}(\mathrm{SR})_{2}\right]_{6}\left(\mathrm{R}=\mathrm{CH}_{2} \mathrm{CH}_{3}\right.$ [51], $\left(\mathrm{CH}_{2}\right)_{2} \mathrm{CH}_{3}$ [52], $\left(\mathrm{CH}_{2}\right)_{3} \mathrm{CH}_{3}$ [53], $\left(\mathrm{CH}_{2}\right)_{5} \mathrm{CH}_{3}$ [14], $\left(\mathrm{CH}_{2}\right)_{11} \mathrm{CH}_{3}$ [46], $\mathrm{C}_{2} \mathrm{H}_{4} \mathrm{C}_{6} \mathrm{H}_{5}$ [15], $\mathrm{CH}_{2} \mathrm{COOCH}_{3}$ [54], $\mathrm{CH}_{2}-$
$\mathrm{CH}_{2} \mathrm{OH}$ [55]) complexes and nickel-thiolate complexes [8-10].

FT-IR absorbance measurement (Fig. S2) of the as-synthesized Pd-thiolate complex exhibits vibration bands corresponding to $\left[\mathrm{Pd}\left(\mathrm{SCH}_{3}\right)_{2}\right]_{6}$ molecule. Three peaks at 2920, 2904 and $2813 \mathrm{~cm}^{-1}$ are attributed to the asymmetric and symmetric stretching vibrations of the $\mathrm{C}-\mathrm{H}$ bond. Peaks at around 1542, 1416 and $1306 \mathrm{~cm}^{-1}$ are assigned to the deformation vibrations of the $\mathrm{C}-\mathrm{H}$ bond. A strong peak at $952 \mathrm{~cm}^{-1}$ is indexed to the stretching vibration of the $\mathrm{C}-\mathrm{S}$ bond. All these peaks give supplementary evidence to confirm the formation of $\mathrm{Pd}$-thiolate complex compound. The $\mathrm{Pd}_{6}$ clusters (dissolved in chloroform) show four distinct absorption bands centered at 415, 367, 322 and 273 nm (Fig. S3), similar to those previously reported for $\left[\mathrm{Pd}\left(\mathrm{SC}_{2} \mathrm{H}_{4} \mathrm{Ph}\right)_{2}\right]_{6}[15]$. This indicates that our samples are indeed $\mathrm{Pd}_{6}$.

\section{Characterization and morphological control of $\left[\operatorname{Pd}\left(\mathrm{SCH}_{3}\right)_{2}\right]_{6}$ assemblies}

SEM images of the $\left[\mathrm{Pd}\left(\mathrm{SCH}_{3}\right)_{2}\right]_{6}$ microprisms are shown in Fig. 2. The large-area SEM image reveals the uniformity and relatively prismatic nature of the $\left[\mathrm{Pd}\left(\mathrm{SCH}_{3}\right)_{2}\right]_{6} \mathrm{mi}-$ crostructures, which have an average length of 3-4 $\mu \mathrm{m}$, and an average diameter of $1.2-1.5 \mu \mathrm{m}$. The inset shows a single piece of $\left[\mathrm{Pd}\left(\mathrm{SCH}_{3}\right)_{2}\right]_{6}$, which indicates the prismlike morphology of the $\left[\mathrm{Pd}\left(\mathrm{SCH}_{3}\right)_{2}\right]_{6}$ crystal. EDS result (Fig. S4) suggests that the sample contains both palladium and sulfur. As a result of electron beam irradiation, the $\left[\mathrm{Pd}\left(\mathrm{SCH}_{3}\right)_{2}\right]_{6}$ microstructure visibly and rapidly degraded

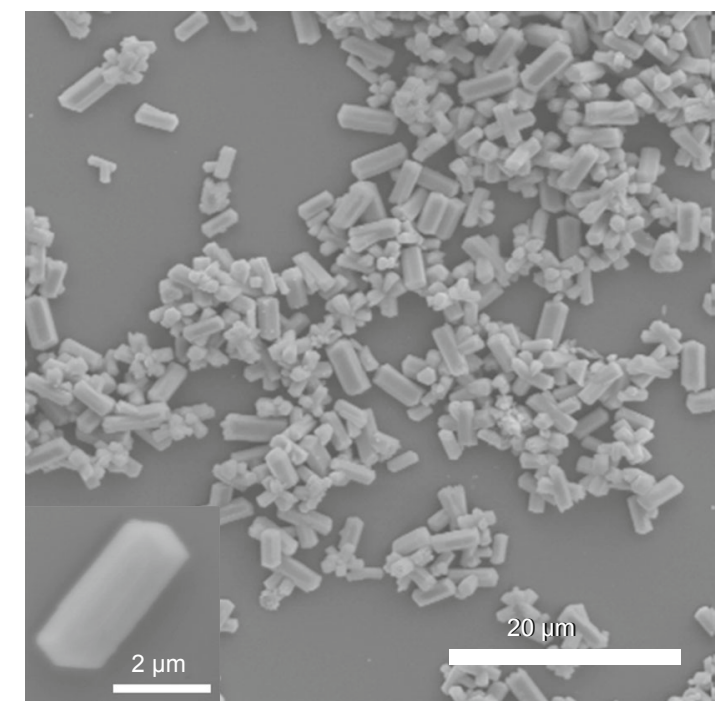

Figure 2 Low magnification SEM image of the as-prepared $\left[\mathrm{Pd}\left(\mathrm{SCH}_{3}\right)_{2}\right]_{6}$ microprisms. Inset shows SEM image of a single $\left[\mathrm{Pd}\left(\mathrm{SCH}_{3}\right)_{2}\right]_{6}$ microprism. 


\section{during imaging.}

The $\left[\mathrm{Pd}\left(\mathrm{SCH}_{3}\right)_{2}\right]_{6}$ nanospheres were synthesized under the same experimental condition except for the addition of the surfactant molecule, CTAB. The large-area SEM and TEM images of the $\left[\mathrm{Pd}\left(\mathrm{SCH}_{3}\right)_{2}\right]_{6}$ nanospheres shown in Figs $3 \mathrm{a}$ and $\mathrm{b}$ reveal that by introducing long alkyl chain surfactant, the morphology of the $\left[\mathrm{Pd}\left(\mathrm{SCH}_{3}\right)_{2}\right]_{6}$ crystals can be finely tuned to nearly monodispersed spherical nanostructures, which have an average diameter of 0.28 $\pm 0.03 \mu \mathrm{m}$. The inset in Fig. $3 \mathrm{~b}$ shows a single crystal of $\left[\mathrm{Pd}\left(\mathrm{SCH}_{3}\right)_{2}\right]_{6}$ nanosphere, which indicates the sphere-like morphology of the $\left[\mathrm{Pd}\left(\mathrm{SCH}_{3}\right)_{2}\right]_{6}$ crystal. The XRD pattern demonstrates the composition of the nanospheres is identical with the microprisms (Fig. 3c). Compared to the pattern of the prismatic sample as shown in Fig. 2, the spherical counterpart shows the broadened peaks and a weak peak at $\sim 11.7^{\circ}$, indicating the smaller grain size. Size distribution diagram is shown in Fig. 3d, which confirms a narrow size distribution of the samples.

a

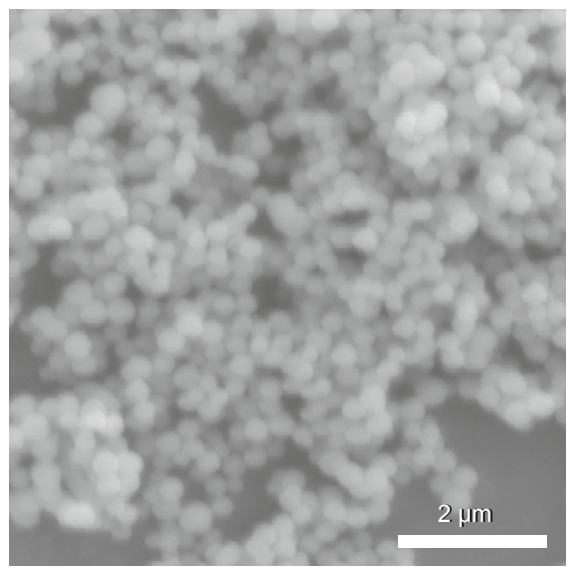

c

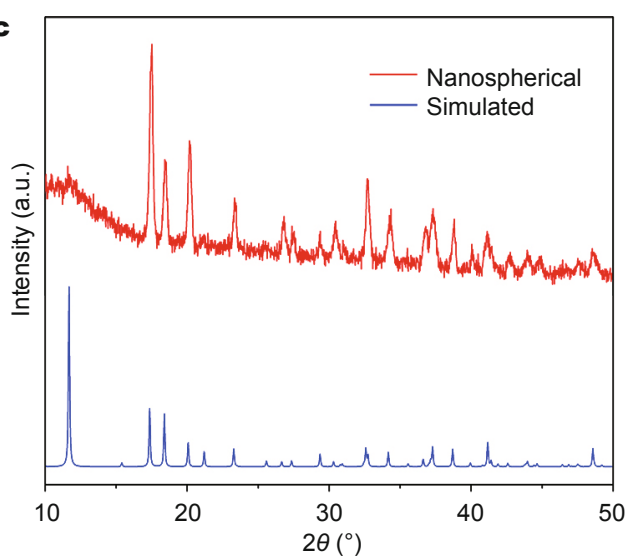

\section{Thermolysis of $\left[\mathrm{Pd}\left(\mathrm{SCH}_{3}\right)_{2}\right]_{6}$ assemblies}

We studied the thermal stability of the as-prepared $\left[\mathrm{Pd}\left(\mathrm{SCH}_{3}\right)_{2}\right]_{6}$ microprisms. The TGA curve was measured under air atmosphere from room temperature to $350^{\circ} \mathrm{C}$ with a temperature ramp of $2^{\circ} \mathrm{C} \mathrm{min}^{-1}$. The TGA results are given in Fig. 4. The decomposition of $\mathrm{Pd}$-thiolate complex under air atmosphere begins at $210^{\circ} \mathrm{C}$ and ends at about $270^{\circ} \mathrm{C}$, which corresponds to the loss of hydrocarbon part and sulfur moiety. According to the empirical formula, $\mathrm{PdS}_{2} \mathrm{C}_{2} \mathrm{H}_{6}$, the ideal weight loss percentage should be $47.0 \%$. However, the actual total weight loss of $45.3 \%$ is slightly less than the theoretical value of $47.0 \%$. The weight percentage increase in air, $1.7 \%$, suggests that only partial oxidation takes place while some $\mathrm{Pd}(0)$ still keeps zero-valent even at high temperature under air atmosphere. Then, thermolysis study of the Pd-thiolate assemblies were carried out under both air and argon condition. Pd and various Pd sulfides were obtained at different temperature and atmosphere. The details of the thermal decomposition experiments

b
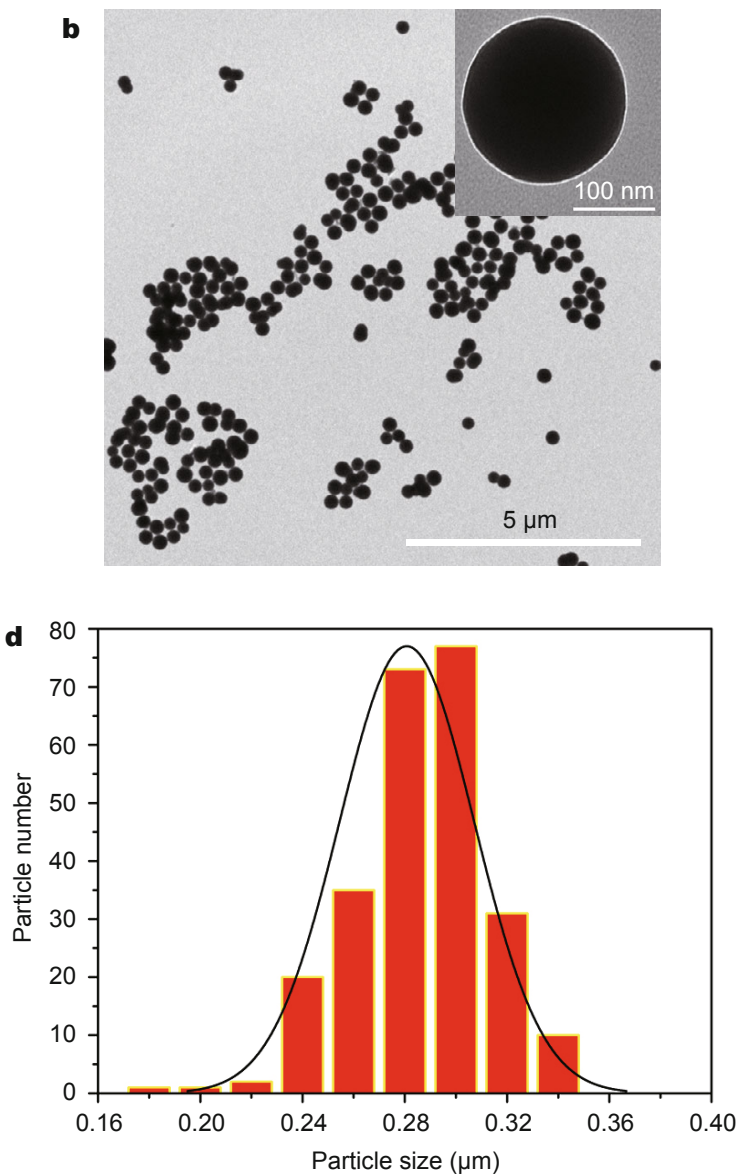

Figure 3 Typical low-magnification SEM (a) and TEM (b) images of $\left[\mathrm{Pd}\left(\mathrm{SCH}_{3}\right)_{2}\right]_{6}$ nanospheres. The inset image shows the spherical morphology of a single $\left[\mathrm{Pd}\left(\mathrm{SCH}_{3}\right)_{2}\right]_{6}$ nanosphere. (c) XRD pattern of $\left[\mathrm{Pd}\left(\mathrm{SCH}_{3}\right)_{2}\right]_{6}$ nanospheres (red) and the calculated pattern (black). (d) Size distribution of $\left[\mathrm{Pd}(\mathrm{SCH})_{2}\right]_{6}$ nanospheres. 


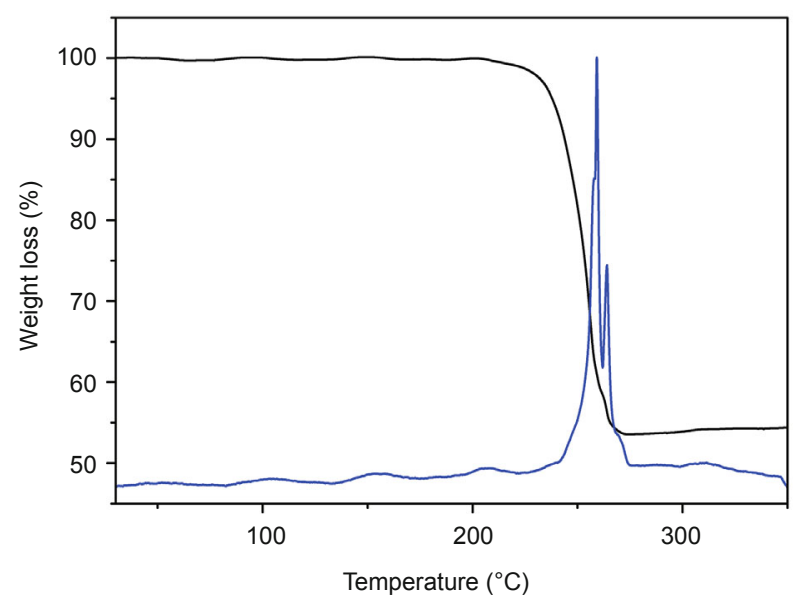

Figure 4 TGA curves of the pristine $\left[\mathrm{Pd}\left(\mathrm{SCH}_{3}\right)_{2}\right]_{6}$ microprisms.

are listed in Table 1. It shows that the sulfide composition of the cluster can be completely removed at $350^{\circ} \mathrm{C}$ under air atmosphere. However, this cannot be achieved even in much higher temperature under argon condition, indicates that the oxygen plays an important role in removing the sulfide in the assemblies.
Table 1 Thermolysis results of $\left[\mathrm{Pd}\left(\mathrm{SCH}_{3}\right)_{2}\right]_{6}$ microprisms (MPs) and nanospheres (NSs) in conditions with different temperature and atmosphere

\begin{tabular}{|c|c|c|c|}
\hline Starting materials & Temperature $\left({ }^{\circ} \mathrm{C}\right)^{\mathrm{a}}$ & Atmosphere & Product \\
\hline MPs & 280 & Air & $\mathrm{Pd}_{4} \mathrm{~S}$ \\
\hline MPs & 300 & Air & $\mathrm{Pd}+\mathrm{Pd}_{4} \mathrm{~S}$ \\
\hline MPs & 350 & Air & $\mathrm{Pd}$ \\
\hline NSs & 280 & Air & $\mathrm{Pd}_{32} \mathrm{~S}_{14}$ \\
\hline NSs & 350 & Air & $\mathrm{Pd}_{32} \mathrm{~S}_{14}$ \\
\hline NSs & 200 & Argon & Pd-thiolate \\
\hline NSs & 410 & Argon & $\mathrm{Pd}_{16} \mathrm{~S}_{7}$ \\
\hline $\mathrm{NSs}^{\mathrm{b}}$ & 700 & Argon & $\mathrm{Pd}+\mathrm{Pd}_{4} \mathrm{~S}$ \\
\hline
\end{tabular}

a) Ramp rate was $5^{\circ} \mathrm{C} \mathrm{min}^{-1}$ and kept at this temperature for $2 \mathrm{~h}$ b) Loaded on activated carbon $20 \mathrm{wt} . \%$.

For further understanding the thermolysis process, the morphology of the palladium product, which was obtained at $350^{\circ} \mathrm{C}$ under air condition, was characterized by SEM. Fig. $5 \mathrm{a}$ shows a representative SEM image of nanoporous palladium at low magnification. It can be seen that pristine prism-like morphology kept intact after thermolysis. The
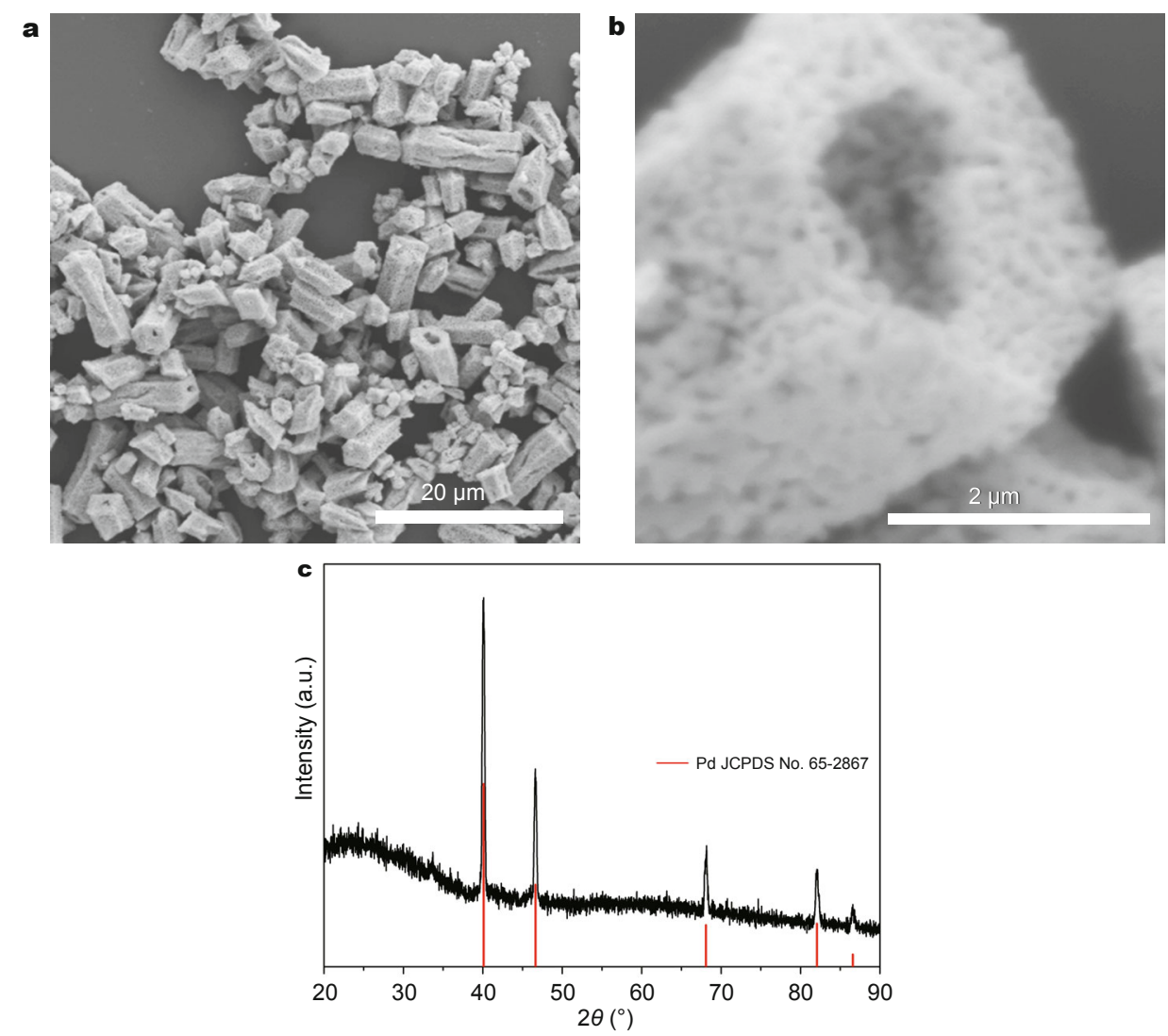

Figure 5 Low-magnification (a) and partial enlargement (b) images of the nanoporous palladium. (c) XRD pattern of the product after TGA analysis. 
enlarged image shown in Fig. $5 \mathrm{~b}$ reveals that after thermal decomposition, the product shows an interesting continuous 3D porous structure with a hollow center. XRD pattern of the pyrolysis product is shown in Fig. $5 c$, which unequivocally suggests that the product is phase-pure Pd with face-centered cubic ( $\mathrm{fcc}$ ) structure, implying the complete decomposition of $\mathrm{Pd}$-thiolate complex to palladium metal.

\section{CONCLUSIONS}

In summary, a tiara-like $\mathrm{Pd}(\mathrm{II})$ thiolate complex, $\left[\mathrm{Pd}\left(\mathrm{SCH}_{3}\right)_{2}\right]_{6}$, was formed through a novel method, in which DMSO with better availability and moderate smell was used instead of $\mathrm{CH}_{3} \mathrm{SH}$, and the reaction mechanism was also discussed. We further investigated the morphology evolution by introducing a surfactant regent, and successfully obtained monodisperse nanospheres without changing other conditions. This method can be easily extended to other morphology by changing the surfactant's type and chain length. Furthermore, the related palladium and palladium sulfides could be obtained through simple thermal decomposition of $\left[\mathrm{Pd}\left(\mathrm{SCH}_{3}\right)_{2}\right]_{6}$ assemblies. We expect that this convenient method could be extended to longer alkyl chain sulfoxides, or even other metals (nickel) which can also form similar tiara-like thiolate clusters. This work will offer an important way for designing and fabricating palladium and palladium sulfides with particular structures.

Received 3 December 2015; accepted 24 December 2015; published online 28 December 2015

1 Alemany P, Hoffmann R. Toroidal nickel thiolates: structure and bonding. J Am Chem Soc, 1993, 115: 8290-8297

2 Krebs B, Henkel G. Transition-metal thiolates: from molecular fragments of sulfidic solids to models for active centers in biomolecules. Angew Chem Int Ed, 1991, 30: 769-788

3 Dance IG. The structural chemistry of metal thiolate complexes. Polyhedron, 1986, 5: 1037-1104

4 Desireddy A, Conn BE, Guo J, et al. Ultrastable silver nanoparticles. Nature, 2013, 501: 399-402

5 Jadzinsky PD, Calero G, Ackerson CJ, Bushnell DA, Kornberg RD. Structure of a thiol monolayer-protected gold nanoparticle at $1.1 \AA$ resolution. Science, 2007, 318: 430-433

6 Hsu IJ, Hsieh CH, Ke SC, et al. New members of a class of iron-thiolate-nitrosyl compounds: trinuclear iron-thiolate-nitrosyl complexes containing $\mathrm{Fe}_{3} \mathrm{~S}_{6}$ core. J Am Chem Soc, 2007, 129: 1151-1159

7 Eichhofer A, Andrushko V, Bodenstein T, Fink K. Trinuclear early/ late-transition-metal thiolate complexes. Eur J Inorg Chem, 2014, 3510-3520

8 Jian FF, Jiao K, Li Y, Zhao PS, Lu LD. $\left[\mathrm{Ni}_{6}\left(\mathrm{SCH}_{2} \mathrm{CH}_{2} \mathrm{OH}\right)_{12}\right]$ : a double crown [12]metallacrown-6 nickel(II) cluster. Angew Chem Int Ed, 2003, 42: 5722-5724

9 Woodward P, Dahl LF, Abel EW, Crosse BC. A new type of cyclic transition metal complex, $\left[\mathrm{Ni}\left(\mathrm{SC}_{2} \mathrm{H}_{5}\right)_{2}\right]_{6}$. J Am Chem Soc, 1965, 87: 5251-5253

10 Zhu M, Zhou S, Yao C, Liao L, Wu Z. Reduction-resistant and re- duction-catalytic double-crown nickel nanoclusters. Nanoscale, 2014, 6: 14195-14199

11 Yang HY, Wang Y, Yan JZ, et al. Structural evolution of atomically precise thiolated bimetallic $\left[\mathrm{Au}_{12+n} \mathrm{Cu}_{32}(\mathrm{SR})_{30+n}\right]^{4-}(n=0,2,4,6)$ nanoclusters. J Am Chem Soc, 2014, 136: 7197-7200

12 Melzer MM, Mossin S, Cardenas AJP, et al. A copper(II) thiolate from reductive cleavage of an S-nitrosothiol. Inorg Chem, 2012, 51: 8658-8660

13 Ibrahim MM, Seebacher J, Steinfeld G, Vahrenkamp H. Tris(thloimidazolyl)borate-zinc-thiolate complexes for the modeling of biological thiolate alkylations. Inorg Chem, 2005, 44: 8531-8538

14 Ananikov VP, Orlov NV, Zalesskiy SS, et al. Catalytic adaptive recognition of thiol $(\mathrm{SH})$ and selenol $(\mathrm{SeH})$ groups toward synthesis of functionalized vinyl monomers. J Am Chem Soc, 2012, 134: 6637-6649

15 Chen J, Liu L, Weng L, et al. Synthesis and properties evolution of a family of tiara-like phenylethanethiolated palladium nanoclusters. Sci Rep, 2015, 5: 16628

16 Anson CE, Eichhöfer A, Issac I, et al. Synthesis and crystal structures of the ligand-stabilized silver chalcogenide clusters $\left[\mathrm{Ag}_{154} \mathrm{Se}_{77}(\mathrm{dp}\right.$ pxy $\left.)_{18}\right], \quad\left[\mathrm{Ag}_{320}(\mathrm{~S} t \mathrm{Bu})_{60} \mathrm{~S}_{130}(\mathrm{dppp})_{12}\right], \quad\left[\mathrm{Ag}_{352} \mathrm{~S}_{128}\left(\mathrm{~S}_{\mathrm{C}} \mathrm{C}_{5} \mathrm{H}_{11}\right)_{96}\right]$, and $\left[\mathrm{Ag}_{490} \mathrm{~S}_{188}\left(\mathrm{~S}_{\mathrm{C}} \mathrm{C}_{5} \mathrm{H}_{11}\right)_{114}\right]$. Angew Chem Int Ed, 2008, 47: 1326-1331

17 Chakraborty I, Govindarajan A, Erusappan J, et al. The superstable $25 \mathrm{kDa}$ monolayer protected silver nanoparticle: measurements and interpretation as an icosahedral $\mathrm{Ag}_{152}\left(\mathrm{SCH}_{2} \mathrm{CH}_{2} \mathrm{Ph}\right)_{60}$ cluster. Nano Lett, 2012, 12: 5861-5866

18 Albrecht C, Schwieger S, Bruhn C, et al. Alkylthio bridged 44 cve triangular platinum clusters: synthesis, oxidation, degradation, ligand substitution, and quantum chemical calculations. J Am Chem Soc, 2007, 129: 4551-4566

19 Heaven MW, Dass A, White PS, Holt KM, Murray RW. Crystal structure of the gold nanoparticle $\left[\mathrm{N}\left(\mathrm{C}_{8} \mathrm{H}_{17}\right)_{4}\right]\left[\mathrm{Au}_{25}\left(\mathrm{SCH}_{2} \mathrm{CH}_{2} \mathrm{Ph}\right)_{18}\right]$. J Am Chem Soc, 2008, 130: 3754-3755

20 Chong $\mathrm{H}$, Li P, Wang S, et al. $\mathrm{Au}_{25}$ clusters as electron-transfer catalysts induced the intramolecular cascade reaction of 2-nitrobenzonitrile. Sci Rep, 2013, 3: 3214

$21 \mathrm{Li} \mathrm{G}$, Zeng $\mathrm{C}$, Jin $\mathrm{R}$. Thermally robust $\mathrm{Au}_{99}(\mathrm{SPh})_{42}$ nanoclusters for chemoselective hydrogenation of nitrobenzaldehyde derivatives in water. J Am Chem Soc, 2014, 136: 3673-3679

22 Li G, Lei Z, Wang QM. Luminescent molecular Ag-S nanocluster $\left[\mathrm{Ag}_{62} \mathrm{~S}_{13}\left(\mathrm{SBu}^{\mathrm{t}}\right)_{32}\right]\left(\mathrm{BF}_{4}\right)_{4}$. J Am Chem Soc, 2010, 132: 17678-17679

23 Udaya Bhaskara Rao T, Pradeep T. Luminescent $\mathrm{Ag}_{7}$ and $\mathrm{Ag}_{8}$ clusters by interfacial synthesis. Angew Chem Int Ed, 2010, 49: 39253929

24 Zhu M, Aikens CM, Hendrich MP, et al. Reversible switching of magnetism in thiolate-protected $\mathrm{Au}_{25}$ superatoms. J Am Chem Soc, 2009, 131: 2490-2492

25 Antonello S, Perera NV, Ruzzi M, Gascón JA, Maran F. Interplay of charge state, lability, and magnetism in the molecule-like $\mathrm{Au}_{25}(\mathrm{SR})_{18}$ cluster. J Am Chem Soc, 2013, 135: 15585-15594

26 Wu ZN, Li YC, Liu JL, et al. Colloidal self-assembly of catalytic copper nanoclusters into ultrathin ribbons. Angew Chem Int Ed, 2014, 53: 12196-12200

27 Wu ZN, Dong CW, Li YC, et al. Self-assembly of Au-15 into single-cluster-thick sheets at the interface of two miscible high-boiling solvents. Angew Chem Int Ed, 2013, 52: 9952-9955

28 Li L, Wang Q. Spontaneous self-assembly of silver nanoparticles into lamellar structured silver nanoleaves. ACS Nano, 2013, 7: 3053-3060

29 Liu Y, Wu ZN, Zhang H. Deriving the colloidal synthesis of crystalline nanosheets to create self-assembly monolayers of nanoclusters. Adv Colloid Interface Sci, 2014, 207: 347-360

30 Jia XF, Li J, Wang EK. Supramolecular self-assembly of morpholo- 
gy-dependent luminescent Ag nanoclusters. Chem Commun, 2014, 50: 9565-9568

31 Beletskaya IP, Cheprakov AV. The heck reaction as a sharpening stone of palladium catalysis. Chem Rev, 2000, 100: 3009-3066

32 Jiang B, Song S, Wang J, et al. Nitrogen-doped graphene supported Pd@PdO core-shell clusters for C-C coupling reactions. Nano Res, 2014, 7: 1280-1290

33 Wang Z, Chen W, Han Z, et al. Pd embedded in porous carbon (Pd@ CMK-3) as an active catalyst for Suzuki reactions: accelerating mass transfer to enhance the reaction rate. Nano Res, 2014, 7: 1254-1262

34 Long R, Wu D, Li Y, et al. Enhancing the catalytic efficiency of the Heck coupling reaction by forming $5 \mathrm{~nm}$ Pd octahedrons using kinetic control. Nano Res, 2015, 8: 2115-2123

35 Li L, Zhou C, Zhao H, Wang R. Spatial control of palladium nanoparticles in flexible click-based porous organic polymers for hydrogenation of olefins and nitrobenzene. Nano Res, 2015, 8: 709-721

36 Xu B, Yang H, Zhou G, Wang X. Strong metal-support interaction in size-controlled monodisperse palladium-hematite nano-heterostructures during a liquid-solid heterogeneous catalysis. Sci China Mater, 2014, 57: 34-41

37 Gao D, Zhou H, Wang J, et al. Size-dependent electrocatalytic reduction of $\mathrm{CO}_{2}$ over Pd nanoparticles. J Am Chem Soc, 2015, 4288-4291

38 Huang H, Bao S, Chen Q, et al. Novel hydrogen storage properties of palladium nanocrystals activated by a pentagonal cyclic twinned structure. Nano Res, 2015, 8: 2698-2705

39 Huang XQ, Tang SH, Mu XL, et al. Freestanding palladium nanosheets with plasmonic and catalytic properties. Nat Nanotechnol, 2011, 6: 28-32

40 Mashkina AV, Sakhaltueva LG. Gas-phase thiophene hydrogenation to tetrahydrothiophene over sulfide catalysts. Kinet Catal, 2002, 43: 107-114

41 Raybaud P, Hafner J, Kresse G, Toulhoat H. Ab initio density functional studies of transition-metal sulphides: II. electronic structure. J Phys Condens Matter, 1997, 9: 11107

42 Dey S, Jain VK. Platinum group metal chalcogenides. Platinum Met Rev, 2004, 48: 16-29

43 Bladon JJ, Lamola A, Lytle FW, et al. A palladium sulfide catalyst for electrolytic plating. J Electrochem Soc, 1996, 143: 1206-1213

44 Li X, Wen J, Low J, Fang Y, Yu J. Design and fabrication of semiconductor photocatalyst for photocatalytic reduction of $\mathrm{CO}_{2}$ to solar fuel. Sci China Mater, 2014, 57: 70-100

45 Liu J, Zhao Y, Liu J, et al. From $\mathrm{Cu}_{2} \mathrm{~S}$ nanocrystals to $\mathrm{Cu}$ doped CdS nanocrystals through cation exchange: controlled synthesis, optical properties and their p-type conductivity research. Sci China Mater, 2015, 58: 693-703

46 Yang ZQ, Smetana AB, Sorensen CM, Klabunde KJ. Synthesis and characterization of a new tiara $\mathrm{Pd}(\mathrm{II})$ thiolate complex,
$\left[\mathrm{Pd}\left(\mathrm{SC}_{12} \mathrm{H}_{25}\right)_{2}\right]_{6}$, and its solution-phase thermolysis to prepare nearly monodisperse palladium sulfide nanoparticles. Inorg Chem, 2007, 46: 2427-2431

47 Jose D, Jagirdar BR. Synthesis and characterization of $\operatorname{Pd}(0), \operatorname{PdS}$, and Pd@PdO core-shell nanoparticles by solventless thermolysis of a Pd-thiolate cluster. J Solid State Chem, 2010, 183: 2059-2067

48 Carlsen L, Egsgaard H, Harpp DN. Gas-phase thermolyses 4. Gasphase thermolyses of thietan 1-oxide and 1,2-oxathiolan 2-oxide evidence for the intermediacy of 1,2-oxathiolan. J Chem Soc Perkin Trans 2, 1981, 1166-1170

49 Spek AL. Refcode AFACUG. Cambridge Crystallographic Database, 2007

50 Nobusada K, Yamaki T. Electronic properties of palladium-thiolate complexes with tiara-like structures. J Phys Chem A, 2004, 108: 1813-1817

51 Stash AI, Perepelkova TI, Noskov YG, Buslaeva TM, Romm IP. Palladium clusters $\mathrm{Pd}_{4}(\mathrm{SEt})_{4}(\mathrm{OAc})_{4}$ and $\mathrm{Pd}_{6}(\mathrm{SEt})_{12}$ : structure and properties. Russ J Coord Chem, 2001, 27: 585-590

52 Higgins JD, Suggs JW. Preparation, structure and spectroscopic studies of the palladium mercaptides $\mathrm{Pd}_{8}(\mathrm{~S}-\mathrm{Npr})_{16}$ and $\mathrm{Pd}_{6}(\mathrm{~S}$ $\mathrm{Npr})_{12}$. Inorg Chim Acta, 1988, 145: 247-252

53 Stash AI, Levashova VV, Lebedev SA, et al. Palladium clusters $\mathrm{Pd}_{4}(\mathrm{SR})_{4}(\mathrm{OAc})_{4}$ and $\mathrm{Pd}_{6}(\mathrm{SR})_{12}(\mathrm{R}=\mathrm{Bu}, \mathrm{Ph})$ : structure and properties. Russ J Coord Chem, 2009, 35: 136-141

54 Schneider I, Horner M, Olendzki RN, Strahle J. Structure of cyclo-hexakis [bis- $\mu$-(methoxycarbonylmethylthiolato)-palladium(II)], $\left[\mathrm{Pd}\left(\mathrm{SCH}_{2} \mathrm{COOCH}_{3}\right)_{2}\right]_{6}$. Acta Crystallogr Sect C Cryst Struct Commun, 1993, 49: 2091-2093

55 Mahmudov KT, Hasanov XI, Maharramov AM, et al. A hexanuclear metallacrown palladium(II) cluster derived from 2-mercaptoethanol. Inorg Chem Commun, 2013, 29: 37-39

Acknowledgements This work was supported by the State Key Project of Fundamental Research for Nanoscience and Nanotechnology (2012CB224802), the National Natural Science Foundation of China (21573119, 21221062, 21131004, 21390393, U1463202 and 21325101), and Beijing Municipal Commission of Science and Technology (Z141100003814017).

Author contributions Feng Q and Li J designed and synthesized the samples; Feng Q, Wang W and Cheong WC performed the material characterization; Feng Q and Li J wrote the paper with support from Chen C and Li Y. All authors contributed to the general discussion.

Conflict of interest The authors declare that they have no conflict of interest.

Supplementary information EDS pattern and FT-IR spectra of pristine $\left[\mathrm{Pd}\left(\mathrm{SCH}_{3}\right)_{2}\right]_{6}$ microprisms. BET absorption curve of nanoporous palladium. Powder XRD patterns of the various products after thermolysis. These details are available in the online version of the paper. 


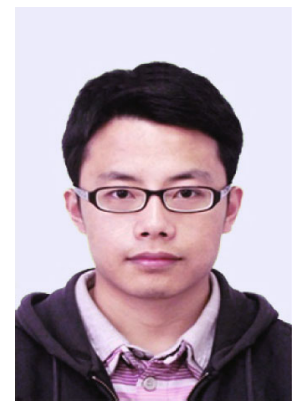

Quanchen Feng received his MSc degree in chemistry from Beihang University in 2013. Currently, he is a PhD candidate in inorganic chemistry under the supervision of Prof. Yadong Li at Tsinghua University. His research interest is mainly focused on the simple synthesis of intermetallic nanomaterials and their applications as heterogeneous catalysts.

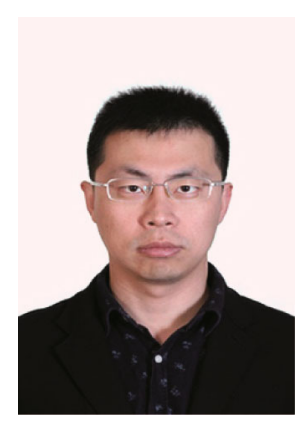

Jinpeng Li received his PhD degree in chemistry from Tohoku University in Japan in 2012. Currently, he is a postdoctoral researcher in the group of Prof. Yadong Li at Tsinghua University. His research focuses on the synthesis of metallic nanomaterial composite and their applications in heterogeneous catalysis.

中文摘要 本文以醋酸钯为钯源, 二甲基亚砜为硫源, 在乙二醇和醋酸存在的条件下通过一步法制备了一种六核钯-甲硫醇团簇化合物 $\left[\mathrm{Pd}\left(\mathrm{SCH}_{3}\right)_{2}\right]_{6}$. 其具有特征的类花冠形结构. 对其反应机制进行了探讨, 首先二甲基亚砜分解生成甲硫醇和甲醛, 钯与甲硫醇反应原位生 成钯-甲硫醇团簇. 这些生成的团簇分子进一步组装成微米尺寸大小的棱柱. 通过向反应体系中引入一种表面活性剂, 产物的形貌从微 米棱柱转变为纳米球. $350^{\circ} \mathrm{C}$ 下, $\left[\mathrm{Pd}\left(\mathrm{SCH}_{3}\right)_{2}\right]_{6}$ 的微米棱柱在空气中分解得到金属钯单质. 对其热解产物进行电镜表征, 发现其在保持原 有棱柱形貌的基础上形成了孔道结构. 在不同的热解条件下可以得到钯或硫化钯热解产物. 